\title{
The Prospect for Occupational Health Nursing Activities in Small and Medium Sized Workplaces
}

\author{
Moon-Hee Jung \\ Department of Nursing, College of Medicine, Hanyang University
}

\begin{abstract}
The Prospect for Occupational Health Nursing Activities in Small and Medium Sized Workplaces: Moon-Hee JuNG. Department of Nursing, College of Medicine, Hanyang University-In Korea, nurses perform their services in different ways according to the scale of the workplace: In large workplaces they work as full-timers and in small and medium ones they work as visiting nurses, placed by health management agencies. Regardless of their ways of service, occupational health nurses conduct a large part of health management affairs. Health management affairs have so far aimed at decreasing occupational diseases, but when working conditions are improved and occupational diseases decrease, their goals will be changed, aiming at the health promotion and the prevention of general diseases which have been steadily increasing. As occupational health nursing activities are expected to be changed to accomplish such goals, the roles of nurses are also expected to be expanded. The expected role of nurses is to provide high quality professional services suitable for the scale of the workplace, the nursing activity methods and the goals of health management. In practice, however, there are not a few restraints on them to adequately perform such roles. Most of all, because of poor working conditions, their turnover is high and their term of service is short. In relation to this, the tendency to replace them with less experienced nurses may give rise to quite a few problems in maintaining reliable relationships with workplaces as well as providing professional services. Therefore, in order to produce high-quality professional services, it is necessary to improve the working conditions of nurses so as to secure nurses who can work for a long time. What is most important is to allow occupational health nurses to perform standard services by function.

(J Occup Health 1999; 41: 47-50)
\end{abstract}

Received July 27, 1998; Accepted Nov 6, 1998

Correspondence to: $M . \cdot H$. Jung, Department of Nursing, College of Medicine, Hanyang University

This paper was orally presented at the 11 th Korea-Japan Joint Conference on Occupational Health, Sorak, Korea, May 10-11, 1998.
Key words: Occupational health nursing activities, Small and medium sized workplace

Workplaces can be classfied into three according to the number of employees. One is large workplaces with more than 300 employees, another is a medium sized ones with 50 to 299 employees, and the third is small ones with 5 to 49 employees ${ }^{11}$.

In Korea, occupational health nurses perform their services in different ways according to the scale of the workplace. In large workplaces they are placed by the workplaces themselves and work full-time. In small and medium sized ones they are placed by health management agencies and perform their services by visiting workplaces ${ }^{1)}$.

In general, small and medium sized workplaces share the following characteristics distinct from those of large ones: 1) Health management affairs are entrusted to a professional 'health managemant agency'. 2) The health management agency manages several workplaces as a group. 3) Occupational health nurses are employed as health managers by the 'health management agency'. 4) The occupational health nurses perform their services by visiting workplaces. 5) The expenses for health management are, in most cases, paid by workplaces, but some small workplaces have been financially supported by the government since 1993 .

These differences between large, medium sized and small workplaces demand distinctive nursing activities by industrial size. We therefore need to examine practical service types of nurses to meet the demands of small and medium sized workplaces.

\section{Present Status of the Placement of Nurses by Industrial Size}

According to the survey report issued by the Ministry of Labor of Korea ${ }^{1)}$, the number of workplaces with more than five employees is approximately 202,000 and the number of employees employed by them was around $6,341,000$ in 1996. Table 1 shows the number of workplaces and employees by industrial size. 
Table 1. Number of workplaces and employees by industrial size (unit: 1,000 )

\begin{tabular}{|c|c|c|c|c|c|c|}
\hline \multirow{2}{*}{ Size } & \multicolumn{2}{|c|}{1992} & \multicolumn{2}{|c|}{1994} & \multicolumn{2}{|c|}{1996} \\
\hline & $\mathrm{N}$ & $\%$ & $\mathrm{~N}$ & $\%$ & $\mathbf{N}$ & $\%$ \\
\hline \multicolumn{7}{|c|}{ Number of workplaces } \\
\hline small & 132 & 86.5 & 156 & 87.7 & 180 & 89.1 \\
\hline medium & 18 & 12.2 & 19 & 11.1 & 20 & 9.9 \\
\hline large & 2 & 1.3 & 2 & 1.2 & 2 & 1.0 \\
\hline total & 153 & 100.0 & 177 & 100.0 & 202 & 100.0 \\
\hline \multicolumn{7}{|c|}{ Number of employees } \\
\hline small & 2,110 & 36.8 & 2,415 & 39.2 & 2,673 & 42.2 \\
\hline medium & 1,944 & 33.9 & 2,033 & 33.3 & 2,056 & 32.4 \\
\hline large & 1,679 & 29.3 & 1,719 & 27.8 & 1,611 & 25.4 \\
\hline total & 5,733 & 100.0 & 6,167 & 100.0 & 6,341 & 100.0 \\
\hline
\end{tabular}

The proportion of small workplaces is over $86 \%$, and the proportion of employees who work in small workplaces is nearly $40 \%$.

Health managers are placed in over $98 \%$ workplaces. They are placed either by workplaces themselves or by health management agencies entrusted by workplaces. The proportions are as shown in Table $2,35.5 \%$ and $64.5 \%$ respectively ${ }^{2}$.

As shown in Table 2, the proportion of nurses is almost $50 \%$ from which we can ascertain that nurses play a large part in health management affairs. Nonetheless, at present nurses cannot perform proper services adequately because of various practical restraints.

\section{Some Restraints on the Performance of Expected Roles}

Table 3 shows the terms of service of nurses employed by a health management agency belonging to Korean Industrial Health Association ${ }^{3}$.

As shown in Table 3, 31.5\% of nurses have been in service for less than one year, $21.9 \%$ for $1-2$ years, $16.5 \%$ for $2-3$ years and $30.1 \%$ for over 3 years. In other words, quite a few nurses leave their posts within 3 years after they are placed. This means that nurses' terms of service are short and their turnover is high. It goes without saying that poor working conditions, basically, cannot motivate them to serve for a long time.

Table 4 shows annual salary of occupational health nurses by institutions they belong to.

According to some recent research data ${ }^{4.5}$, nurses placed by health management agencies are, in general, younger and have 1-2 years shorter experience, and receive less pay than nurses placed by workplaces themselves. But these differences seem to be caused by differences between workplaces and health management agencies in the characteristics of the institutions they belong to rather than differences in qualifications for
Table 2. Types of the Placement of Health Managers and Proportion of Health Managers by Function Placed by Health Management Agencies (23 June '97)

\begin{tabular}{lcr}
\hline Placed & N of workplaces & $\%$ \\
\hline by workplaces & 3,797 & 35.5 \\
by health management agencies & 6,893 & 64.5 \\
total & 10,690 & 100.0 \\
\hline Placed & N of health & \\
by health management agencies & managers & $\%$ \\
\hline & 106 & 21.4 \\
doctor & $243^{*}$ & 49.0 \\
nurse & 136 & 27.4 \\
hygienist & 11 & 2.2 \\
others & 496 & 100.0 \\
total & &
\end{tabular}

*The total number of occupational health nurses in Korea is approximately 2,000. Among them 243 are placed by 64 health management agencies ${ }^{2)}$.

Table 3. Terms of service (31 Dec. '97)

\begin{tabular}{lcr}
\hline Terms of service & $\mathrm{N}$ & $\%$ \\
\hline Over 3 years & 22 & 30.1 \\
2-3 years & 12 & 16.5 \\
1-2 years & 16 & 21.9 \\
Under 1 year & 23 & 31.5 \\
Total & 73 & 100.0 \\
\hline
\end{tabular}

These data are cited from an unpublished internal report of the Korea Industrial Health Association by permission of the Association ${ }^{3)}$. They show the present status of 73 nurses in charge of group health practice who are placed by the Association.

employment, or the salary system. For example, nurses belonging to health management agencies founded by the government are annually paid 5-6 million won (W) more than those belonging to health management agencies founded by unversities.

As the proportion of experienced nurses becomes smaller and the proportion of new nurses becomes larger professioal services provided for workplaces are likely to be poorer. Therefore, the trent toward replacing experienced nurses with new nurses may cause serious problems in maintaining reliable relationships with workplaces.

Another restraint that prevents providing proper services for workplaces is related to the content of college education for occupational health nursing. In Korea there are 42 nursing colleges (4-year system) and 64 junior 
Table 4. Annual salary of nurses by institutions (unit: W 1,000$)$

\begin{tabular}{|c|c|}
\hline $\begin{array}{c}\text { (Full-time nurses) } \\
\text { placed by } \\
\text { workplaces }\end{array}$ & $\begin{array}{l}\text { (Visiting nurses) } \\
\text { belonging to health management } \\
\text { agencies founded by }\end{array}$ \\
\hline \multirow{4}{*}{$1400-1800$} & general hospitals : $1000-1100$ \\
\hline & $: 1500-1600$ \\
\hline & corporations \\
\hline & government \\
\hline
\end{tabular}

colleges og nursing (3-year system). Table 5 shows the present status of college education for occupational health nursing.

Of the total 42 nursing colleges (4-year system), only 4 colleges $(9.5 \%)$ have 'occupational health nursing' as an independent course, and 12 colleges $(28.5 \%)$ have 'practice for occupational health nursing' as a part of 'practice for community health nursing' course ${ }^{6)}$. In the case of junior colleges (3-year system), the situation is much worse ${ }^{7)}$. The reason seems to be that the educational purpose of nursing colleges in Korea is mainly to train general nurses, so that new nursrs, when they are placed as health managers, require time to become practically equipped for their work.

\section{Changes in Goals and Service Content of Health Management}

Health management in workplaces has so far aimed at the prevention of occupational diseases. Yet, as working conditions improve and occupational diseases decrease, its goal is expected to be changed to the prevention of general or age-related diseases which have been regarded as less important. Accordingly, to achieve such a goal, methods and the content of professional services will also have to be changed.

Until now, the management of occupational diseases has been wholly dependent on experts, but from now on it will gradually be changed so that workers themselves manage their diseases. As this trend will be directly reflected in the content of professional services provided by nurses, nurses will be asked to equip themselves with sufficient knowledge and skills for health promotion services as well as for the management of occupational diseases. As a result, the role and function of nurses will be expanded, and the role expected of nurses will be to provide proper professional services according to the size of the workplace, by occupational nursing activities and to suit the aims of health management.

Nevertheless, nurses have a heavy workload. If nurses' workloads become too heavy, it is hard to expect them to provide high-quality services, so that it is important to provide an environment in which nurses can carry out
Table 5. Present status of college education on occupational health nursing*

\begin{tabular}{lcc}
\hline \multicolumn{1}{c}{ Course } & College & Junior college \\
\hline Occupational & 4 & $1 / 14^{* *}$ \\
health nursing & $9.5 \%$ & $7.1 \%$ \\
\hline $\begin{array}{ccc}\text { Practice for occupational } \\
\text { health nursing }\end{array}$ & 12 & $1 / 9 * *$ \\
$\quad$ Total number of school & $28.5 \%$ & $11.1 \%$ \\
\hline
\end{tabular}

*When it comes to postgraduate (continuing) education of health managers, three institutions provide this in Korea. One is the Korea Industrial Safety Corporation (public foundation). The others are the Korea Industrial Health Association and the Korean Association of Occupational Health Nurses (private foundations). Newly employed health managers receive, 34-h obligatory education at the Korea Industrial Safety Corporation. And every other year doctors and hygienists receive 24-h obligatory education at the Korea Industrial Health Association, and nurses at the Korean Association of Occupational Health Nurses. **In the case of junior colleges, the survey was couducted on a limited number of schools. The denominators indicate the number of school surveyed?).

their duties efficiently. It is therefore important to examine the standard services recommended by the expert committee of the Association of Health Management Agencies of Korea ${ }^{8 y}$.

The committee recommends that a total of 52 services be performed by four functional groups-doctors, nurses, hygienists and administrative managers. Of these 52 services, 32 are concerned with nurses' services, from which we can reconfirm that group health management affairs are highly dependent on nurses. Among those 32 services, 18 are major services of occupational health nurses and the others are services which need the cooperation, guidance or support of other functional groups. Considering subjects of service, I reclassified these 18 major services of nurses in Table 6.

When we regard the three major subjects of service as 'individual', 'group' and 'workplaces', the following are the core services provided for each subject: 1) 'Health counselling' is the service most frequenly given to 'individuals'. 2) 'Group health education' is the service given to 'groups' of workers, aimimg at the steady improvement of their learning experiences. 3) 'Health promotion' is the service given to one or more workplaces, campaigning for no smoking, abstinence from drinking, eating habits, prevention of chronic degenerative diseases and so on. These core services are important enough to determine the health level of workplaces. So it is necessary to train nurses to understand even particular cases of practical services, not to speak of proper 
Table 6. Major services of occupational health nurses by subject

\begin{tabular}{|c|c|c|}
\hline Subject & Type of services & $\begin{array}{c}\text { No. of visit } \\
\text { per year }\end{array}$ \\
\hline \multirow{6}{*}{ Individual } & health counselling & 12 \\
\hline & referring to laboratory or screening test & 4 \\
\hline & explaining medical exam. results to workers & 2 \\
\hline & reporting workers suspicious of 0 . diseases $\left(D_{1}\right)$ to the regional office & 2 \\
\hline & referring workers exposed to hazardous materials for secondary exam. & 2 \\
\hline & assessment of health status of workers injured by industrial accidents & if necessary \\
\hline Group & performing group health education & 4 \\
\hline \multirow{11}{*}{ Workplace } & guidance for desirable life style such as no smoking and abstinence from drinking & 4 \\
\hline & guidance for prevention of chronic degenerative diseases & 4 \\
\hline & guidance for balanced diet and nutrition & 4 \\
\hline & hygienic management of general environment in workplaces & 4 \\
\hline & guidance for maintenance and management of first-aid kits in workplaces & 6 \\
\hline & guiding persons in charge of health care in workplaces for their roles and affairs & 6 \\
\hline & filling out management records in workplaces & 12 \\
\hline & reporting on the results of visits to workplaces & 12 \\
\hline & planning for annual health management affairs in workplaces & 1 \\
\hline & evaluation of annual health management affairs in workplaces & 1 \\
\hline & providing information on health care and advice on laws related to industrial health care & if necessary \\
\hline
\end{tabular}

guidelines for performing those core services.

\section{Conclusion and Suggestions}

In conclusion, what is most important in occupational health nursing activities in small and medium workplaces is to provide high-quality professionsl services which can meet the demands of each workplace. To achieve such a goal, I'd like to suggest the following.

1. The services of occupational health nurses should be specialized.

2. Practical educational programs suited to the characteristics of each workplace should be developed and introduced.

3. It is desirable that training for practical services should be supervised by the Association of Health Management Agencies and the training program should be focused on standard services.

4. It is necessary to give nurses various incentives such as prizes, scholarships, overseas training, fees for visiting activities and fees for the purchase of data.

5. The system of treating experienced nurses preferentially needs to be enforced to lower the turnover of nurses and maintain reliable relationships with workplaces.

6. It is desirable to organize a committee to examine cases of industrial-university cooperation and utilize them in a positive way.

\section{References}

1) Korea Ministry of Labor. '97 Survey Report of Establishment of Labor Conditions. Seoul, 1998 (in Korean).

2) Association of Health Management Agencies. A Workshop for the Application of Standard Services of Health Managers by Function. Seoul, 1997, pp2-19 (in Korean).

3) Korean Industrial Health Association. Unpublished internal report. Dec. 1997 (kihatop@chollian.net).

4) Jung MH. A proposal of a nursing model applicable to group occupational health services. J Kor Community Health Nurs Acad Soc 1995; 9: 1-16 (in Korean with English abstract).

5) Kim Y, Cho TR, Chun KJ, Jeong HS. A survey of the working conditions for the occupational health nurse. J Kor Acad Soc Ind Nurs 1996; 5: 73-89 (in Korean with English abstract).

6) Association of Chief Persons on Nursing College in Korea. Present Status of Nursing Education. Seoul, 1997 (in Korean).

7) Song JH, Park SY, Choi YH. Analysis of curricula between junior nursing college program and baccalaureate program for unification of nursing education. Kor Nurse 1994; 33: 76-93 (in Korean).

8) Park JI, Kim KS, Kim HO, et al. Manual of Health Managers by Function for Group Health Practice. Seoul, Association of Health Management Agencies, 1997, pp 83-134 (in Korean). 